\title{
Quality of Project Team in Traditional Project Management Using Fuzzy Numbers
}

\author{
Jan Betta, Joanna Iwko \\ Faculty of Computer Science and Management, Wroclaw University of Science and Technology, Wroclaw, Poland \\ Email address: \\ jan.betta@pwr.edu.pl (J. Betta), joanna.iwko@pwr.edu.pl (J. Iwko) \\ To cite this article: \\ Jan Betta, Joanna Iwko. Quality of Project Team in Traditional Project Management Using Fuzzy Numbers. Journal of Public Policy and \\ Administration. Vol. 3, No. 4, 2019, pp. 92-97. doi: 10.11648/j.jppa.20190304.13
}

Received: October 28, 2019; Accepted: November 19, 2019; Published: November 27, 2019

\begin{abstract}
This paper is a continuation and development of the same authors paper which has been published recently. The presented paper pertains to the notion of quality of project team in traditional project management. A paradox is observed in the state of art of the project team quality in project management. All specialists recognize the exceptional importance of the parameter "quality" for the final result of the project. On the one hand, one can easily find definitions of project quality, quality of product of the project, quality of the project management processes, and so on. On the other hand, a huge number of bibliographical sources considers the project team functioning, as a sine qua non condition of the project success. The notion "project team quality" is quasi absent in the literature. In this paper an approach is proposed to fill in this gap, in the form of a proposal of the model, which defines the project team quality and allows to measure it. The main results of the previous paper of the authors, particularly guidelines for the quality model of the project team, are briefly presented. The paper presented here has a conceptual character. The main part of the paper are guidelines for the quality model of the project team: general assumptions, measure of the quality of team - classical and with use of fuzzy numbers, based on Myers-Briggs method and Belbin test, and finally, an impact of the quality of the project team on the team management is discussed. The objective of this paper is to show the possibility to define the project team quality process, which ensures not only the optimal level of the team quality, but also allows undertake valuable managerial decisions during the project life cycle.
\end{abstract}

Keywords: Project Team, Model of Project Team Quality, Project Team Quality Measure, Fuzzy Numbers

\section{Introduction}

We are witnesses of an interesting phenomenon in the project management science. All experts recognize and claim the exceptional importance of the parameter "quality" for the final result of the project. On the one hand, one can easily find numerous definitions of project quality, product of the project quality, or quality of the project management processes quality management in projects, managing quality in project and project quality management. On the other hand, a large number of bibliographical sources consider the human factor - project team functioning especially, as a sine qua non condition of the project success. Favourite subjects are: leadership, team work, relations, cooperation, synergy effect, team climate, project team structures, motivation, psychological abilities of the team members, and so one. Extremely seldom appears the term "quality" with reference to the project team. In the literature of the subject, in relation to the team, the concept of the quality appears only as "relationship quality among team members" or "teamwork quality". This phenomenon is incomprehensible in juxtaposition with the statements above.

This paper is a continuation - development of the recent paper of the same authors, in which an attempt has been made to fill in this gap - at least partially - in the form of a proposal of the process, which defines the project team quality and allows to measure this quality [1]. This paper has a conceptual character. Its objective consists in show the possibility to define the project team quality process, which ensures not only the optimal level of the team quality, but also undertake valuable managerial decisions during the project life cycle, using fuzzy numbers apparatus.

Consecutively, have been presented:

A. Literature review of the success of project and success of project management [2-7].

B. Project team work (team work, project manager and 
project team relationships, selection of the project team members and project team dynamics, leadership, selection of the project team members and project team dynamics [8-16].

C. In the central section 3. Of the previous paper, the Guidelines for the Quality Model of the Project Team are presented: general assumptions, quality of team measure - classical and with use fuzzy numbers, based on Myers-Briggs method and Belbin test, and finally, an impact of the quality of the project team on team management is discussed [1]. The Guidelines are briefly presented (cited) below, in the section 2. It is necessary to show and understand the development of the model presented here. The development mainly consists in fuzzy numbers apparatus, introduced to measure the quality of the project team.

\section{Guidelines for the Project Team Quality Model Development}

\subsection{Generalities}

The standards of the project management have some reference to quality management systems, but much less attention is given to this issue than to processes in the project life cycle. The reason for this is largely in the uniqueness of project management [17]. "Quality” is of the exceptional importance for the final result of the project. In the literature there are many definitions of project quality, quality management in projects, managing quality in project and project quality management [18-21]. Secondly, many publications are devoted to the human factor (a project team) as a necessary condition for the project success. In publications from the area of the project team, quality appears e.g. in issues as teamwork quality and relationship quality among team members [22-23]. From the very beginning, the quality management gurus emphasized the importance of the human factor as a quality dimension (also for the manufacturing and service sectors) [24-28]. In ISO 9000: 2015 standard quality is defined as "the degree to which a set of inherent characteristics of an object fulfils requirements" [29]. The definitions of quality used in project management literature are often also based on this definition. For example PRINCE2 uses the ISO definition of quality that sounds like: "the totality of features and inherent or assigned characteristics of a product, person, process, service and/or system that bear on its ability to show that it meets expectations or satisfies stated needs, requirements or specification" [30]. Project management uses the philosophy of Total Quality Management, which can be defined as the application of tools and techniques to understand, manage and meet customer expectations [9]. The special characteristics of projects require special tools and techniques or applications of those tools adapted to projects. To be able to successfully implement Total Quality Management in project management, a project must be client-focused, goal-directed, and people-oriented.
The differences between applying TQM to projects and applying TQM to the manufacturing reflect the differences between project management and general management. Management skills are very important and necessary in both the manufacturing and project environment. A good project manager can adopt quality management approaches and techniques to project. Projects offer some challenges that require different skills, tools and techniques. There are many differences between quality in project management and in manufacturing. According to Darnall they are related to customer, time (improvement process and team building), focus, measurement, roles and responsibilities [9].

The project team doesn't have the structure and organization of a plant and this is why it needs to develop a way to focus the project. It is very important to define very clearly what the project team wants to achieve, who is responsible for the various parts, and track progress toward goals so the project manager knows if the project team is making the right kind of progress. Defining what the project team want to achieve is focus and tracking progress toward goals is measurement.

The model is based on the following assumptions:

a) The model does not take into account technical competences of the project team members; they are supposed fulfilled.

b) The model consider currently recognized psychological aspects of the project team quality only.

c) Project quality level depends growing on the project management quality level

d) Project management quality level depends growing on the project team quality level as well as on the quality level of relations project manager-team.

e) Project team quality level as well as the quality level of relations project manager-team, depends growing on quality level of the members psychological profiles, set down using MBTI and Belbin methods..

f) Quality parameters are measured classically (in percent, e.g.). Nevertheless, it is also possible and useful introduce the measurement using fuzzy numbers apparatus [1].

It is very important to define the quality of project team, because extremely seldom appears the term "quality" with reference to the project team. It is worth adding that if it cannot be defined, it cannot be measured, and if it cannot be measured, it cannot be controlled and improved.

Using the above mentioned definition of quality contained in the ISO 9000: 2015 standard, the quality of project team can be defined as "the degree to which a set of inherent characteristics of the project team fulfils requirements". Requirements mean the need or expectation which has, inter alia, been established. The requirements often apply to customers, but they may nevertheless be the requirements of the organization itself. In this paper, requirements for the project team are primarily the responsibility of the project manager, who is responsible for the level of project management quality, which is affected by the level of quality of the project team and the level of quality of relations 
between the project manager and the team. The requirements for the project team are also defined in cooperation with a psychologist and PR expert. Together with PM, they decide on the optimal proportions of roles at each stage of the project.

According to the authors of the paper, "the quality of project team" is the degree of adaptation of the quality level of psychological profiles of the members of the project team to the requirements of particular phases of the project and requirements of $\mathrm{PM}$, taking into account the nature of the project. This is a refinement of the definition of quality taken from the ISO 9000 standards [1].

\subsection{Measurement of the Quality of Project Team}

Let us imagine a project starting in a company. The main challenge for the Project Manager (PM) and one of principal factor of the project's success is a valuable project team building [8]. The model concerns psychological aspects only, much more sophisticated and equipped always with some level of uncertainty greater than the technical aspects of the problem. The authors did not find any attempt, how the project team quality could be measured. In the paper, the quality of project team measurement is proposed as a process, described below as the sequence of three steps.

1st Step. Let us use MBTI first as the tool of a preliminary selection. From among the set of all employs dispositional, the group is selected, according to criteria: all sixteen types of MBTI are represented, if possible equilibrated, each of them represented by the people with his highest score of his leading feature (in percent), of the MBTI test. Such group will be called a Reference Resource Group (RRG), ensuring the best quality of the project team, taking into account existing people availability. Let us denote such ideal level of the group quality as RQPT (Reference Quality of Project Team). Let $\mathrm{BPIQ}_{\mathrm{i}}$ denotes the Best Personal Individual Qualities levels ( $\mathrm{i}=1,2, \ldots$ 16) for all sixteen psychological types. Then let us define the RQPT level by (1).

$$
\mathrm{RQPT}=\frac{1}{16} \sum_{\mathrm{i}=1}^{16} \mathrm{BPIQi}
$$

2nd Step. There are three main applications of MBTI in development of the project team [8]. It is used for the personnel recruitment, diagnose of the psychological sources of conflicts and improvement of interpersonal relations PM project team.

Project personnel recruitment. Every project is more or less specific; there exist many different types of projects. Moreover, in classical project management approach, the project is divided into five stages: 1. initialisation, 2. planning, 3. execution, 4. control and 5. closing [31]. Each of these stages has its specificity and requires people with different psychological MBTI. So, for each stage, a specific recruitment should be done, taking into account stage's specificity and specificity of the project itself. Such recruitment should be done by Project Manager, Psychologist and HR expert, and the candidates be grounded in RRG. For example, in the stage of planning, the dominant types should be ENTJ or INTJ (extravert or introvert, intuitive, thinking, judging), and so one, for other stages of the project. For a stage $\mathrm{k}(\mathrm{k}=1,2,3,4,5)$, such team should be composed with the people owning psychological types in proportions defined by PM, Psychologist and HR specialist. Let $\mathrm{ST}_{\mathrm{k}}$ be a specific team for a project's stage $\mathrm{k}(\mathrm{k}=1,2,3,4,5)$. Its reference quality $-\mathrm{RQST}_{\mathrm{k}}-$ is given by (2).

$$
\mathrm{RQST}_{\mathrm{k}}=\frac{1}{\mathrm{n}} \sum_{\mathrm{i}=1}^{\mathrm{n}} \text { BPIQi, }
$$

where $\mathrm{BPIQ}_{\mathrm{i}}$ is the Best Personal Individual Quality of the person $\mathrm{i}$, and $\mathrm{n}$ is the number of members of the specific team for the given stage.

The real quality of such team is in reality inferior, because of resources really available for a given stage. It is calculated according to the formula like above, but the (Best) Personal Individual Qualities $\left(\mathrm{BPIQ}_{\mathrm{i}}\right)$ are not the best, but the real ones.

Diagnosis of the psychological sources of conflicts. MBTI method is useful to diagnose reasons of conflicts, inevitable during the life cycle of the project. There can be many different sources of such conflicts and different people involved with them - e.g. PM, his superiors, his workers, customers. More the conflict's reason is of psychological nature, more effective turns out MBTI method to prevent and often solve it. Such prevention and solution of conflicts should be done using RQST ${ }_{k}$, by PM, Psychologist and HR specialist.

Improvement of interpersonal relations PM-Project Team. The PM duties and scope of activities are different than those of the project team members. Usually, the tasks of the project team members are much more precisely defined than those of PM. That's why, very often the psychological type of PM and his team members are essentially different. Project Manager must know his own type, know the types of his people and absolutely be conscious of their differences. It allows him to understand better the differences, propose to the team and undertake common actions which contributes to partially compensate these divergences.

Third step. This is the final step of the project team members selection. It relays on Belbin method, presented in s. 3.3. The nine roles of Belbin are: Leader, Practical organiser, Locomotive, Plant (strategist, visionary), External Coordinator, Judge-Evaluator, Team-worker, Completer Finisher, Specialist. Belbin team roles can be assigned to persons as a result of special Test Belbin [15]. Belbin method recommends the equal distribution of the roles among the team members. However, not all are always required at the same time, e.g. in consecutive phases of the project team lifetime. The decision about the optimal proportions of the roles in respective stages of the project is undertaken by PM, Psychologist and HR expert.

These roles are attributed to the members of a specific team $\left(\mathrm{ST}_{\mathrm{k}}\right)$ for a project's stage $\mathrm{k}(\mathrm{k}=1,2,3,4,5)$ by $\mathrm{PM}$, Psychologist and HR specialist. Such team $-T_{k}$ is optimal, and its quality level is a reference $-\mathrm{RQT}_{\mathrm{k}}$. Each other composition of $\mathrm{T}_{\mathrm{k}}$ (in the case of inaccessibility of all people 
desired), has a lower then reference final level of quality $\mathrm{FQT}_{\mathrm{k}}$, calculated as a correction, which is a result of nonoptimal distribution of the roles. All three (PM as leader, Psychologist and HR specialist) discuss the style and manner of management of the team $T_{k}$ with non-optimal distribution of the roles. This situation is discussed in the next section.

\section{Measurement of the Quality of Project Team using Fuzzy Numbers}

\subsection{Fuzzy Numbers - Basic Notions}

For some reasons, probabilistic methods are not always sufficient for modelling unknown values. Two situations can occur while estimating an unknown value of a parameter:

i. An expert, estimating an unknown value, gives different degrees of possible realization for different, potentially possible intervals.

ii. Among several experts estimating an unknown value $\tilde{A}$, there are some who admit larger intervals of the estimating value realization, and another ones propose the intervals narrower.

In both cases, the estimation of an unknown value is not an interval, but a set of intervals, called a fuzzy number [33]. For this paper objective, let us adopt definitions, properties and dependencies below [32].

Definition 1

A fuzzy number $\tilde{A}$ is a set of real closed intervals $\left\{A^{t}\right\}$ $(t \in[0,1])$, accomplishing the following conditions:

$$
\begin{gathered}
\mathrm{t}<\mathrm{r} \Rightarrow \mathrm{A}^{\mathrm{r}} \subseteq \mathrm{A}^{\mathrm{t}}, \\
\mathrm{I} \subseteq .[0,1] \Rightarrow \mathrm{A}^{\text {supI }}=\bigcap_{\mathrm{r} \in \mathrm{I}} \mathrm{A}^{\mathrm{r}} .
\end{gathered}
$$

\section{Definition 2}

For a fixed $t \in[0,1]$, the interval $A^{t}$ is named t-level of a fuzzy number $\tilde{A}$.

The level $\mathrm{A}^{1-\mathrm{t}}$ corresponds to the opinion of the expert, cautious at the degree $t$. If $\mathrm{t}<\mathrm{r}, \mathrm{A}^{\mathrm{r}}$ is the estimation of an expert less reserved or better informed than the author of the estimation $\mathrm{A}^{\mathrm{t}}$.

\subsection{Application of Fuzzy Numbers to Model the Project Team Quality}

Our object of interest are the parameters, essential for correctness of the final selection (Step 3., sec. 3.2) and recruitment of project teams members in consecutive five stages $\mathrm{ST}_{\mathrm{k}}, \mathrm{k}=1,2, \ldots 5$ (sec. 3.2). According to sec. 3.2, the situation ii. will only be taken into account. There are three experts - PM, Psychologist and HR specialist, who estimate the levels of nine parameters of Belbin. The parameters, defining respective roles, are in fact a mix of various psychological features/predispositions, and it is impossible to attribute to each of them an exact value. The solution is offered by fuzzy numbers apparatus. Let us denote the parameters, defining respective roles, as fuzzy numbers below:
Table 1. Belbin roles and their parameters as fuzzy numbers. Source authors.

\begin{tabular}{ll}
\hline BELBIN ROLE & PARAMETER (FUZZY NUMBER) \\
\hline Leader & $\Re 1$ \\
Practical organiser & $\mathfrak{R} 2$ \\
Locomotive & $\mathfrak{R} 3$ \\
Plant (strategist, visionary) & $\mathfrak{R} 4$ \\
External Coordinator & $\mathfrak{R} 5$ \\
Judge-Evaluator & $\mathfrak{R} 6$ \\
Team-worker & $\Re 7$ \\
Completer Finisher & $\mathfrak{R} 8$ \\
Specialist & $\mathfrak{R} 9$ \\
\hline
\end{tabular}

Example: Let us admit the percentile scale of all possible estimations of - for example - fuzzy number $\mathfrak{R} 1$ values. For the given person, expert1 (PM) can, for instance, state that his estimation of this parameter is [40\%-70\%] with level 0.8 . Expert 2 (Psychologist) can see another possibility - [20\%$80 \%$ ] with level 0.5 . The third one (HR specialist) estimates this value as $[20 \%-80 \%]$ with level 0.7 . So, PM defines the parameter Leader rather exactly ([40\%-70\%]), but with relatively small degree of caution $1-0.8=0.2$. It means that he estimates $\mathfrak{R} 1$ relatively exact, but with a big possibility 0.8 , of mistake. The second (Psychologist's) estimation is less exact ([20\%-80\%]), but with average degree 0.5 of caution. Finally, the third expert (HR specialist) proposes the same interval as the Psychologist, but with caution 0.3. This procedure is of course done also for other eight parameters $\mathfrak{R} 2-\mathfrak{R} 9$.

How do three experts should proceed to manage appropriately the team? This question is discussed in the next sub-section.

\section{Impact of the Quality of Project Team on Team Management}

Classical approach

Step 1 (MBTI): Reference Quality of Project Team level, calculated by the Eq. 1., should be permanently keep at the highest level possible. From point of view of PM it means that at this stage, he should monitoring this level, and in the case of its raising, react by adequate personnel decisions, by substitution - if necessary - some members for another ones.

Step 2 (MBTI): $\mathrm{ST}_{\mathrm{k}}$ is a specific team for a project's stage $\mathrm{k}(\mathrm{k}=1,2,3,4,5)$. Its reference quality - $\mathrm{RQST}_{\mathrm{k}}$ - is given by the Eq. 2. Its monitoring and reaction of PM is necessary as above.

Step 3 (Belbin - classical approach): Nine roles are attributed to the members of a specific team $\left(\mathrm{ST}_{\mathrm{k}}\right)$ for a project's stage $\mathrm{k}(\mathrm{k}=1,2,3,4,5)$ by $\mathrm{PM}$. Such team $-\mathrm{T}_{\mathrm{k}}$, is optimal from point of view of necessary roles proportions, and its quality level is a reference one $-\mathrm{RQT}_{\mathrm{k}}$. Each other composition of $\mathrm{T}_{\mathrm{k}}$, in the case of inaccessibility of all people desired, should be quickly detected by PM, who should undertake adequate decisions, concerning substitutions. In fact, intending make proportion of roles in $T_{k}$ the nearest possible to the ideal - the $\mathrm{RQT}_{\mathrm{k}}, \mathrm{PM}$ would like fulfil the necessary, but not sufficient condition of the best level of the team management. The main disadvantage of this step are, arbitrary enough proposed by three managers, the personal 
roles in $T_{k}$. The roles depend of many factors; in practice, each of the decision-makers estimates the ability of every of team members to play a most appropriate role in $T_{k}$, taking into account not only the Belbin tests results, but also his own experience and personal acquaintance of members. Their estimations can differ between them. It could be very difficult to achieve a consensus on the roles attribution, because of the fact that Belbin roles are based on different, non-measurable and non-comparable, psychological features. As useful appears fuzzy numbers apparatus.

Step 3 (Belbin, non-classical - fuzzy numbers approach)

Let us come back to the example, sub-section 3.2. The estimations of three experts of the role of leader, are defined by three levels of a fuzzy number $\mathfrak{R} 1$. The situation is shown in the Table 2.

Table 2. Estimations of parameter $\Re 1$, source authors.

\begin{tabular}{llll}
\hline & Estimations of $\mathfrak{R} \mathbf{1}$ & Caution level & Comments \\
\hline PM & {$[40 \%-70 \%]$} & 0.2 & Focused on small interval, little cautious or well informed \\
Psychologist & {$[20 \%-80 \%]$} & 0.5 & Big interval of estimation (inexact), cautious average \\
HR Specialist & {$[20 \%-80 \%]$} & 0.3 & Big interval of estimation (inexact), cautious little \\
\hline
\end{tabular}

The differences between estimations could result from two factors. First, from very equilibrate two or more leading roles of the person (Belbin test). Secondly, from personal differences between experts: professional experience, personal acquaintance and subjectivity of perception.

The authors proposal is to organise a consensus meeting of three experts. The consensus meeting consists in substantial argumentation, using facts only [10]. It creates an opportunity to explain the nature of differences between estimations of the values of the fuzzy number $\mathfrak{R} 1$, representing the role of the leader. Let us notice the same intervals of Psychologist and HR expert in the analysed example, but different levels of caution. HR expert can e.g. explain, that he knows well this person, because of common work in several projects in the past. So, he is less cautious than Psychologist and his estimation could be considered as more valuable. The PM interval is twice smaller than two other, but his experience as PM says that his Belbin result is sufficient to attribute him such precise estimation of the role Leader. So, the final result of such (simulated) consensus meeting could be: the interval [40\%-70\%] and caution 0.3 .

Both methods - MBTI and Belbin - were developed to insure the optimal composition of the project team, but taking into account different criteria. According to MBTI, optimisation is done in the triple sense: personnel recruitment, diagnosis of the psychological sources of conflicts and improvement of interpersonal relations PM project team. Application of MBTI as the tool of a preliminary selection, allows to create the Reference Resource Group (RRG), which is a set of people, potentially the best fulfilling the psychological criteria of the method (step 1, subsection 4.2). In the step 2, based on the RRG, $\mathrm{ST}_{\mathrm{k}}$ - specific teams for each of five project's stage are selected. It allows to diagnosis the reasons of conflicts and undertake managerial decisions to prevent them. Moreover, the step 2 encourages PM to make efforts to neutralise, dangerous for the project, differences between his profile and the profiles of his team. Finally, Belbin method facilitates the next, very important decision - the essence of the step 3. This is the decision of optimal proportions of the roles in respective stages of the project. It is impossible to attribute to each role a real value. Therefore, the application of fuzzy number apparatus makes possible to model the parameters, defining respective roles, which depend on various psychological features/predispositions. One can say that fuzzy numbers apparatus opens the space of consensus deliberations on psychological aspects of team work. On each stage, in the case of decreasing of quality level, PM should be open and creative to try raise this level. At all stages, managerial decisions are undertaken by PM, assisted by Psychologist and HR expert.

\section{Conclusions}

Quality is a very large notion, affecting many objects products, services, processes and other forms of human activities. In technical area, definition and measure of quality are evident and easy to formulate. In social sciences, the challenge is much more sophisticated, because of the higher level of differentiation/variation social of systems in comparison with technical ones [10]. Project team is a social group of affiliation, with its complicated structure, processes, and interpersonal relations. The significant role of such team in the project success or failure has inspired the authors to develop an idea of project team quality. This development has been presented in sections: 1 (introduction and theoretical background), 2 (Guidelines for the Project Team Quality Model Development), 3 (the central one - Measurement of the Quality of Project Team using Fuzzy Numbers) and 4 (Impact of the quality of project team on team management).

Guidelines are presented in the form of the process. This process is described by: general fundamentals of the project team quality, assumptions of its validity, methods of quality measurement, and impact of the quality of the project team on team management. The process is based exclusively on psychological parameters of MBTI for the preliminary selection of the project team members, and Belbin method for the final selection of them. For the final selection of the project team members, the fuzzy approach of Belbin parameters and quality measurement have been proposed and justified.

This paper, in line with authors knowledge, is the first attempt to the quality of project team. The authors are conscious of its shortages. So, further research should be done. Theoretical, focused on enrichment of a set of quality psychological parameters by the new ones, analysis the quality using particular cases of fuzzy numbers (triangular, 
trapezoidal), and introducing also fuzzy numbers of type 2 or higher. Practical - research to test and improve the proposed guidelines. And, finally, the similar study could be done on project team quality in projects, managed according to not classical, but agile methodologies, Scrum particularly [34].

Nowadays, quality is omnipresent in all areas of human activities. So, in "projects age", quality of project team is entirely worthy of researchers and practitioners interest.

\section{Fund}

This research was supported by the National Science Centre (Poland), under Grant 394311, 2017/27/B/HS4/01881:"Selected methods supporting project management, taking into consideration various stakeholder groups and using type-2 fuzzy numbers".

\section{References}

[1] Betta J., Iwko J., Draft of Project Team Quality Model in Traditional Project Management, Proceedings of FEBM Conference, Atlantis Press, 2019.

[2] Wysocki R. K., Effective project Management, Edition HELION, 2017, in polish.

[3] https://standishgroup.com/about [access: 27.01.2019].

[4] Highsmith J., APM: Agile Project Management. How develop innovative products, Warsaw, Mikom, 2005, in polish.

[5] ICB - IPMA Competence Baseline -ver. 3.0, Red. Dałkowski B., Staśto L., Zalewski M., Gdańsk, Editor IPMA Poland, 2009 , in polish.

[6] Spałek S., Critical factors of success in project management, Silesian University of Technology, Gliwice, 2004, in polish.

[7] Wong Z., Human factors in project management, San Francisco, Jossey-Bass, 2007.

[8] Frame J. D., Managing Projects in Organisations. How to Make the Best Use of Time, Techniques and People. JosseyBass Inc., Publishers, 1995.

[9] Darnall R. W., The World's Greatest Project. One Project Team on the Path to Quality. A Project Management Institute Book, 1996.

[10] Ortsman O., Quel travail pour demeain? Dunod, Paris, 1995.

[11] Janusz K., Wiśniewska J. (ed.), Project Management in Organisation, Difin, Warsaw, 2014, in polish.

[12] Pittenger D. J., Measuring the MBTI... And Coming Up Short http://www.myersbriggs.org/my-mbti-personality-type/mbtibasics.

[13] Kopczewski M., Szwarc E., Using MBTI technique in project team building, http://www.ptzp.org.pl/files/konferencje/kzz/artyk_pdf_2009/ 065_Kopczewski_Szwarc_a2.pdf, in polish.

[14] Belbin M., Team Roles at Work, Gdansk Psychological Editions, Gdańsk 2008, in polish.
[15] Pracownia Testów, https://www.blog.pracowniatestow.com/index.php/testypsychologiczne/coaching-kariery/test-rol-zespolowych/, in polish.

[16] Hersey P., Blanchard K. H., Management of organizational behavior, Englewood Cliffs, New Jersey 1988.

[17] Wawak S., Wybrane cechy jakości w zarządzaniu projektami, Quality Journal 2018, no 1, in polish.

[18] Heisler S. I., Project quality and the project manager, International Journal of Project Management 1990, Volume 8, Issue 3.

[19] Anderson S. D., Project quality and project managers, International Journal of Project Management 1992, Volume 10 , Issue 3.

[20] Chang Y. F., Ishii H., Fuzzy Multiple Criteria Decision Making Approach to assess the Project Quality Management in Project, Procedia Computer Science 2013, no 22.

[21] Basu R., Managing quality in projects: An empirical study, International Journal of Project Management 2014, no 32.

[22] Ling F. Y. Y., Ning Y., Ke Y., Kumaraswamy M. M., Modeling relational transaction and relationship quality among team members in public projects in Hong Kong, Automation in Construction 2013, no 36.

[23] Lindsjørn Y., Sjøberg D. I. K., Dingsøyr T., Bergersen G. R., Dybå T., Teamwork quality and project success in software development: A survey of agile development teams, The Journal of Systems and Software 2016, no 122.

[24] Feigenbaum A. V., Total Quality Control. McGraw-Hill, New York 1983.

[25] Deming W. E., Out of the Crisis. MIT Press 1986.

[26] Juran J. M., Juran on Leadership for Quality: an executive handbook. Free Press, New York 1989.

[27] Bank J., The essence of total quality management, Prentice Hall International, London 1992.

[28] Crosby Ph., Quality is free: the art of making quality certain. McGraw-Hill, New York 1992.

[29] ISO 9000: 2015 - Quality management systems Fundamentals and vocabulary.

[30] Prince 2 - Projects in Controlled Environment, Office of Government Commerce, London 2009.

[31] Project Management Institute Inc., A Guide To The Project Management Body of Knowledge (PMBOK® Guide - Sixth Edition), 2017.

[32] Kuchta D., Soft mathematics in Management, Wroclaw University of Science and Technology ed. 2001, in polish.

[33] Zadeh L. A., Fuzzy Sets. Information and Control no 8, 1965.

[34] Schwaber K., Sutherland J., The Scrum Guide. The Definitive Guide to Scrum: The Rules of the Game, https://www.scrumguides.org/docs/scrumguide/v2017/2017Scrum-Guide-US.pdf. 